\title{
Effects of dextromethorphan and oxycodone on treatment of neuropathic pain in mice
}

\author{
Pao-Pao Yang ${ }^{1,2}$, Geng-Chang Yeh', Eagle Yi-Kung Huang ${ }^{2}$, Ping-Yee Law ${ }^{3}$, Horace H. Loh ${ }^{3}$ and Pao-Luh Tao ${ }^{2,4^{*}}$
}

\begin{abstract}
Background: Neuropathic pain is a very troublesome and difficult pain to treat. Although opioids are the best analgesics for cancer and surgical pain in clinic, only oxycodone among opioids shows better efficacy to alleviate neuropathic pain. However, many side effects associated with the use of oxycodone render the continued use of it in neuropathic pain treatment undesirable. Hence, we explored whether dextromethorphan (DM, a known $\mathrm{N}$-methyl-D-aspartate receptor antagonist with neuroprotective properties) could potentiate the anti-allodynic effect of oxycodone and underlying mechanisms regarding to glial cells (astrocytes and microglia) activation and proinflammatory cytokines release in a spinal nerve injury (SNL) mice model.

Results: Oxycodone produced a dose-dependent anti-allodynic effect. Co-administration of DM at a dose of $10 \mathrm{mg} / \mathrm{kg}$ (i.p.) (DM10) which had no anti-allodynic effect by itself enhanced the acute oxycodone $(1 \mathrm{mg} / \mathrm{kg}$, s.c.) effect. When the chronic anti-allodynic effects were examined, co-administration of DM10 also significantly enhanced the oxycodone effect at $3 \mathrm{mg} / \mathrm{kg}$. Furthermore, oxycodone decreased SNL-induced activation of glial cells (astrocytes and microglia) and plasma levels of proinflammatory cytokines (IL-6, IL-1 $\beta$ and TNF-a). Co-administration of DM10 potentiated these effects of oxycodone.

Conclusion: The combined use of DM with oxycodone may have therapeutic potential for decreasing the effective dose of oxycodone on the treatment of neuropathic pain. Attenuation of the glial activation and proinflammatory cytokines in the spinal cord may be important mechanisms for these effects of DM.
\end{abstract}

Keywords: Oxycodone, Dextromethorphan, Spinal nerve ligation, Neuropathic pain, Allodynia

\section{Background}

Neuropathic pain is caused by a primary lesion or dysfunction in the somatosensory system. Symptoms of neuropathic pain may include hyperalgesia (increased sensitivity to noxious stimulus) and allodynia (in which low-threshold stimuli, such as brushing of the skin, can evoke pain) [1]. Neuropathic pain can be very difficult to treat with only $40-60 \%$ of people achieving partial relief [2]. Some animal studies have suggested that activated microglia in spinal cord may play a vital role in nerve injury induced neuropathic pain [3, 4].

Opioid receptor agonists, such as morphine and oxycodone are highly effective strong analgesics for relief of

\footnotetext{
* Correspondence: pltao@nhri.org.tw

2Department of Pharmacology, National Defense Medical Center, 161, Sec. 6, Minquan E. Rd., Neihu Dist., Taipei City 114, Taiwan

${ }^{4}$ Center for Neuropsychiatric Research, National Health Research Institutes, 35 Keyan Road, Zhunan, Miaoli County, 35053 Taiwan, ROC

Full list of author information is available at the end of the article
}

moderate or severe pain. However, morphine is less effective in treating neuropathic pain. Chronic morphine exposure increased glial expression and enhanced proinflammatory cytokines in the L5 spinal cord of L5 nerveinjured rats. This enhanced glial expression followed by the loss of the analgesic effect of morphine (so called tolerance) [5]. Oxycodone is a semisynthetic opioid analgesic derived from a naturally occurring alkaloid, thebaine. It has been used in clinic since 1917 and is increasingly used worldwide to treat acute and chronic pain. Several reports have shown that oxycodone effectively relieved neuropathic pain in clinic $[6,7]$. It is more effective than morphine in the mice models of painful diabetic neuropathy $[7,8]$ and sciatic nerve ligation-induced neuropathic pain [9]. Spinal nerve ligation induced down regulation of $\mathrm{GABA}_{\mathrm{B}}$ expression which was prevented by inhibition of microglia activation in the spinal cord dorsal horn [10]. Recent study by Thibault et al. provided evidence that the long-term analgesic effect of oxycodone but not morphine 
is due to an up-regulation in $\mathrm{GABA}_{\mathrm{B}}$ receptor expression in sensory neurons and subsequently reinforce a presynaptic inhibition [11]. Therefore, the first aim of our study was to investigate whether chronic oxycodone treatment could suppress the glial activation and proinflammatory cytokines in a mice model of spinal nerve injury.

Dextromethorphan (DM) has been used in clinics as an antitussive agent (15-30 mg, 3 to 4 times per day in adult) for more than 50 years [12]. It can act as low affinity non-competitive N-methyl-D-aspartate (NMDA) receptor antagonist [13], $\alpha 3 \beta 4$-nicotinic receptor antagonist [14], and sigma-1 receptor agonist [15]. Our previous studies showed that DM could effectively reduce the rewarding effects (i.e., addiction potential) and drug-seeking effects of morphine $[16,17]$ or methamphetamine $[18,19]$ in rats. DM also has important neuroprotective properties in various CNS injury models, including ischemia, seizure, and traumatic brain injury paradigms [20]. Co-administration of L-NAME (nitric oxide synthase inhibitor) and DM prevented pathological pain in sciatic nerve ligation induced neuropathy in the chronic constriction injury (CCI) model [21]. DM blocks LPS-induced microglial activation in a concentration-dependent manner in vitro $[22,23]$ and also inhibits methamphetamine-induced microglial activation in vivo [22]. Many of these effects of DM seem functionally related to its inhibitory effects on glutamate-induced neurotoxicity via NMDA receptors or voltage-gated calcium channel activities [24]. Since oxycodone still has high abused and addictive potential and all the side effects of opiates at the therapeutic doses, the second aim of our study was to investigate whether DM at a dose that did not have anti-allodynic effect by itself could potentiate the effect of oxycodone on treatment of neuropathic pain and therefore decrease the effective dose of oxycodone in a mice model. The underlying mechanisms regarding to suppression of glia activation and proinflammatory cytokines were also investigated in the present study.

\section{Methods}

\section{Animals}

One hundred and twenty three adult male C57BL/6 J mice (25-30 g; from mating of the parental C57BL/6 J strain) were used in this study. The animals were kept in an animal room with a 12-h light/dark cycle, at a temperature of $25 \pm 2{ }^{\circ} \mathrm{C}$ and humidity of $55 \%$ at the Animal Center of Taiwan's National Defense Medical Center, which is accredited by AAALAC International. Standard diet and water were provided ad libitum during the experiment. The care of animals was carried out in accordance with institutional and international standards (Principles of Laboratory Animal Care, NIH), and the protocol was approved by the Institutional Animal Care and Use Committee (IACUC) of National Defense Medical Center, Taiwan, ROC. All studies involving animals are reported in accordance with the ARRIVE guidelines [25].

\section{Spinal nerve ligation (SNL) surgery}

L5 SNL was carried out according to a previously described method for rats [26] and modified for mice in our laboratory [27]. The mice were deeply anesthetized with sodium pentobarbital $(80 \mathrm{mg} / \mathrm{kg}$, i.p.), and the hairs on their back were clipped. A midline incision above the lumbar spine exposed the left sixth lumbar transverse process. The transverse process was removed carefully with a small scraper. The underlying fifth lumbar nerve root was isolated and then tightly ligated with $8-0$ nylon thread. Next, the wound was closed with 2-3 muscle sutures (3-0 absorbable nylon suture) and 4-5 skin sutures (3-0 nonabsorbable nylon suture). The surgical procedure for the sham group was identical, except that the fifth lumbar spinal nerve was not ligated and transected.

\section{Experimental schedule and groups}

As shown in Fig. 1, a 14-day schedule was used in this study. Drug(s) was/were administered from $2 \mathrm{~h}$ after spinal nerve ligation surgery in mice (once on day 0 and day 14 , twice a day from day 1 to day 13). Von Frey tests were used for measuring mechanical allodynia every other day. Two tests were carried out in mice on each test day. The first one was tested $1 \mathrm{~h}$ before drug(s) administration, in order to see the development of allodynia under chronic drug(s) treatment. The second test was tested $30 \mathrm{~min}$ after drug(s) administration in order to see the acute anti-allodynic effect of drug(s). There were more than 10 groups based on different $\operatorname{drug}(\mathrm{s})$ treatment, such as sham operation with saline treatment (sham + saline), SNL surgery with saline

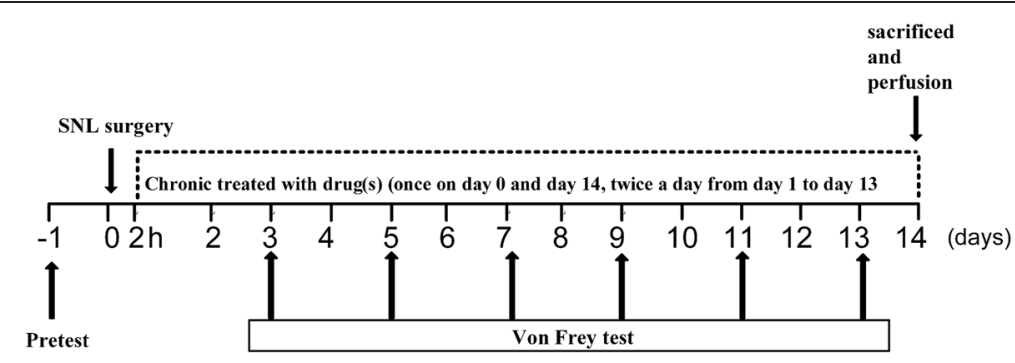

Fig. 1 The schedule of the experiments 
treatment (SNL + saline), SNL surgery with DM treatment $(10 \mathrm{mg} / \mathrm{kg}$, i.p. or $20 \mathrm{mg} / \mathrm{kg}$, i.p.) (SNL + DM10, SNL + DM20), SNL surgery with oxycodone treatment $(1,3$, or $5 \mathrm{mg} / \mathrm{kg}$, s.c.) (SNL + O1, SNL + O3 or $\mathrm{SNL}+\mathrm{O} 5)$, and SNL surgery with co-treatment with oxycodone (1 or $3 \mathrm{mg} / \mathrm{kg}$, s.c. $)$ and $\mathrm{DM}(10 \mathrm{mg} / \mathrm{kg}$, i.p.) (SNL + O1 + DM or $\mathrm{SNL}+\mathrm{O} 3+\mathrm{DM})$. The animals were given the last drug administration 30 min before sacrificed on day 14 for immunohistochemistry study. The number of animals in each group was at least 8 at the beginning of the experiment; and at least 5 mice in each group survived to complete this study.

\section{Von Frey test for determination of mechanical allodynia}

The mice were individually placed in a transparent acrylic box $(9 \times 9 \times 15 \mathrm{~cm})$ with a wire-mesh bottom and allowed to acclimate to their environment for at least $30 \mathrm{~min}$. The mechanical stimulus was applied from underneath to the plantar aspect of the hind limb, with a gradual increase in pressure by means of an Electronic von Frey apparatus (IITC Inc., CA, USA). The end point was characterized by the removal of the paw followed by clear flinching movements. After the paw withdrawal, the intensity of the pressure was automatically recorded. The test was carried out $1 \mathrm{~h}$ before (pretest) and $30 \mathrm{~min}$ after saline or drug(s) injection. Each test was repeated 3 times with intervals of $5 \mathrm{~min}$, and the average value was used. The area under the time-effect curve (AUC) was calculated for each animal according to the following formula: |(paw withdrawal pressure of each time point) - (paw withdrawal pressure of pre-operative baseline value) $\mid \times$ time (days).

\section{Immunohistofluoresensce for activated spinal astrocytes or microglia}

Mice were anesthetized with pentobarbital $(80 \mathrm{mg} / \mathrm{kg}$ i.p.) 30 min after saline or drug administration on day 14 and perfused with Tyrode's calcium-free buffer $(116 \mathrm{mM}$ $\mathrm{NaCl} / 5.36 \mathrm{mM} \mathrm{KCl} / 1.57 \mathrm{mM} \mathrm{MgCl}_{2} \cdot 6 \mathrm{H}_{2} \mathrm{O} / 0.405 \mathrm{mM}$ $\mathrm{MgSO}_{4} / 1.23 \mathrm{mM} \mathrm{NaH}{ }_{2} \mathrm{PO}_{4} / 5.55 \mathrm{mMglucose} / 26.2 \mathrm{mM}$ $\mathrm{NaHCO}_{3}$, pH 7.4), followed by $4 \%$ paraformaldehyde in $0.1 \mathrm{M}$ phosphate buffer ( $\mathrm{pH}$ 7.4). The L4-L6 spinal segments were carefully removed, post-fixed in the same fixative for $2 \mathrm{~h}$ at $4{ }^{\circ} \mathrm{C}$, and then placed in $30 \%$ sucrose solution for $48-72 \mathrm{~h}$ at $4{ }^{\circ} \mathrm{C}$. The samples were then embedded in OCT compound and frozen immediately at $-80{ }^{\circ} \mathrm{C}$. Serial transverse spinal cord slices $(10 \mu \mathrm{m})$ were sectioned with a cryostat. The slices were mounted on SuperFrost Plus slides (Menzel-Glaser) and were airdried for $30 \mathrm{~min}$ at room temperature, and washed three times in ice-cold phosphate-buffered saline Tween-20 (PBST). The slices were then fixed by immersing the slides in acetone/methanol $\left(1: 1\right.$, pre-cooled to $\left.-20{ }^{\circ} \mathrm{C}\right)$ for $3 \mathrm{~min}$ and washing them again three times in ice-cold PBST. The sections were then pre-incubated with blocking buffer
(3 \% normal goat serum diluted in PBST) for $1 \mathrm{~h}$ at room temperature. After washing in ice-cold PBST, the sections were incubated overnight at $4{ }^{\circ} \mathrm{C}$ with mouse monoclonal anti-GFAP antibody (1:400; Millipore, Cat \#MAB360) or incubated over 2 nights with rabbit anti-ibal antibody (1:300; Wako), which was diluted in PBS. Following primary antibody incubation, the sections were washed three times with PBST and incubated with the secondary antibody [goat anti-mouse FITC conjugated (1:100, Millipore, Cat \#AP124F), or Alexa Fluro 488 goat anti-rabbit IgG (1:200), which were diluted with blocking buffer] for $1 \mathrm{~h}$ at room temperature. Sections were then washed with PBST, cleared, and cover-slipped by using mounting medium (Serotec, HIS002B). The processed sections were captured using a Leica (DMI 6000B) inverted microscope and a Leica (DFC 420) camera by MetaMorph software (Major Instruments Co., Ltd). Five spinal cord sections from the L5 segments were randomly selected from each mice. So in each group, there were 30 sections obtained for histology quantifications. Images were evaluated by a computer-assisted image analysis program (MetaMorph 6.1). Our image data were collected using the same region and the same size of field within same lamina to avoid any variance and difference in staining between lamina. The immunoreactivities for GFAP and iba1 immunopositive cells within the superficial dorsal horn were averaged the spinal sections for each experimental group.

\section{Quantification of cytokine levels using XMAP technology}

Blood samples were collected on day 2 and day 6 after spinal nerve ligation surgery in mice. Blood was mixed with $1.8 \mathrm{mg} / \mathrm{ml}$ EDTA and put on ice for less than $10 \mathrm{~min}$. Plasma was then collected by centrifugation at $1000 \mathrm{~g}$ for 10 min at $4{ }^{\circ} \mathrm{C}$ and stored at $-80{ }^{\circ} \mathrm{C}$ until analysis. Cytokine levels were determined using the Milliplex MAP mouse cytokine/chemokine kit (Millipore, Billerica, MA, USA; MCYTOMAG-70 K), with specific bead sets - proinflammatory cytokines (IL-6, IL-1 $\beta$, and TNF- $\alpha$ ). The data acquisition and analysis were performed using Milliplex Analyst 5.1.

\section{Statistical analysis}

The data were expressed as means \pm S.E.M. Student's $t$ test, two-way or one-way ANOVA, Bonferroni post hoc test, or Newman-Keuls test were used to analyze the data. A difference was considered to be significant at $p<0.05$.

\section{Results}

Effects of oxycodone on SNL-induced allodynia

We first explored the effects of oxycodone on the mechanical allodynia induced by SNL. The withdrawal pressure for ipsilateral hind paw was significantly decreased from 7-9 $\mathrm{g}$ to around $2 \mathrm{~g}$ on day 3 after SNL surgery (SNL + saline group in Fig. 2a). On the other hand, the sham 

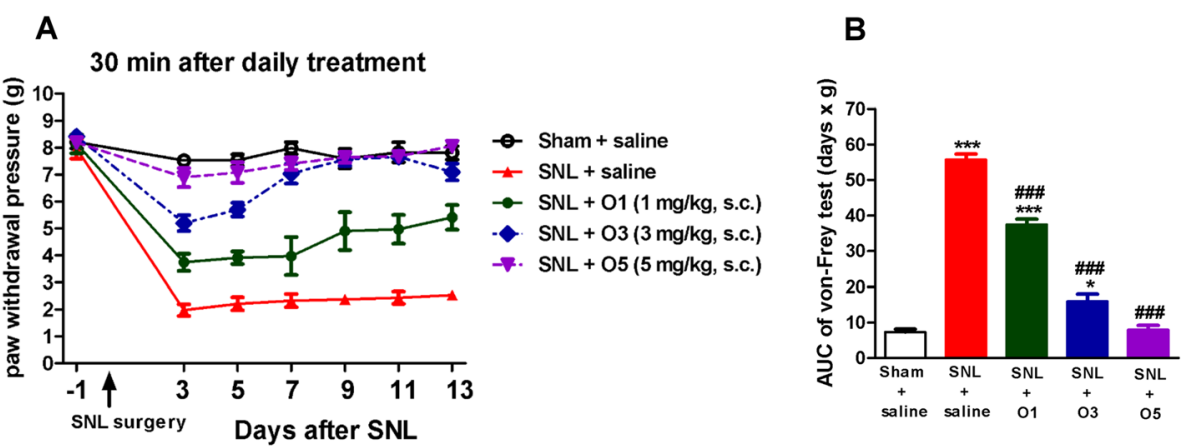

C

D

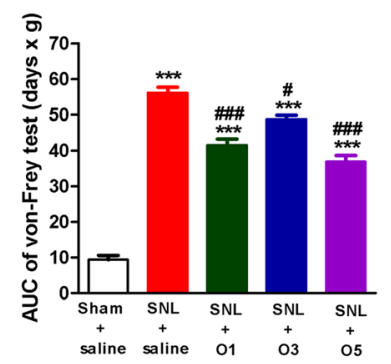

Fig. 2 Oxycodone produced a significant and dose-dependent acute effect on SNL-induced allodynia. The ipsilateral paw withdrawal pressure was determined every other day after SNL by von Frey test. (a) acute effect determined 30 min after daily saline or oxycodone administration, or (c) chronic effect determined $1 \mathrm{~h}$ before saline or oxycodone administration. The area under curve (AUC) values of corresponding curves of the von Frey tests are shown in $(\mathbf{b})$ and $(\mathbf{d})$. Data are presented as means \pm S.E.M. $(n=5-9)$. One-way ANOVA and Newman-Keuls test were used to

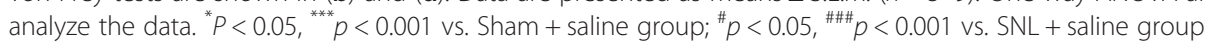

operation did not alter the ipsilateral hind paw withdrawal pressure at all (sham + saline group in Fig. 2a). These results indicate that the allodynia of the ipsilateral hind paw was induced by the ligation of the L5 spinal nerve. The withdrawal pressure of the contralateral side of the nerveligated group did not change significantly through the time course (data not shown).

Furthermore, the withdrawal pressure of the ipsilateral hind paw was determined $1 \mathrm{~h}$ before and also $30 \mathrm{~min}$ after saline or oxycodone treatment (1, 3, or $5 \mathrm{mg} / \mathrm{kg}$, s.c.) every other day. There was a dose-dependent acute anti-allodynic effect of oxycodone when tested 30 min after drug administration, as shown in Fig. 2a. Oxycodone at a dose of $5 \mathrm{mg} /$ $\mathrm{kg}$ (s.c.) completely blocked the allodynia of the ipsilateral hind paw in all test days. The corresponding area under curve (AUC) of the time-effect curves also showed that the oxycodone had a dose-dependent anti-allodynia effect (Fig. 2b). However, this acute effect of oxycodone did not persist. When we measured the withdrawal pressure of the ipsilateral hind paw $1 \mathrm{~h}$ before drug treatment on test days, though there was significant attenuation of the allodynia, the chronic effects of oxycodone were much less than the acute effects of oxycodone [Fig. 2c, d vs. Fig. 2a, b]. These data indicate that oxycodone $(1,3$, or $5 \mathrm{mg} / \mathrm{kg}$, s.c.) not only had an acute anti-allodynic effect but also could improve the chronic course of the SNL-induced allodynia.

\section{Effects of DM on SNL-induced mechanical allodynia}

We next investigated the effects of DM by itself on the mechanical allodynia induced by SNL. As shown in Fig. 3a, $20 \mathrm{mg} / \mathrm{kg}$ of DM (i.p.) produced a minimal but significant anti-allodynia effect in SNL mice (Fig. 3a, SNL + DM20 vs. $\mathrm{SNL}+$ saline group; $p<0.001)$. On the other hand, $10 \mathrm{mg} /$ $\mathrm{kg}$ of DM did not produce any acute anti-allodynia effect after daily drug treatment in SNL mice (SNL + DM10 vs. $\mathrm{SNL}+$ saline group). Neither $10 \mathrm{mg} / \mathrm{kg}$ nor $20 \mathrm{mg} / \mathrm{kg}$ of DM by itself showed significant chronic effects when tests were done $1 \mathrm{~h}$ before drug treatment, as shown in Fig. 4a. Hence, in the following studies, we chose a dose of DM that by itself had no acute anti-allodynic effect, i.e., $10 \mathrm{mg} / \mathrm{kg}$ (i.p.), to co-administer with different submaximal doses of oxycodone (i.e., 1 or $3 \mathrm{mg} / \mathrm{kg}$, s.c.) so as to investigate whether DM could enhance the anti-allodynic effect of oxycodone.

\section{Co-administration of DM with oxycodone on SNL-induced allodynia}

The acute anti-allodynic effect of oxycodone was dosedependent, as previously shown in Fig. 2b. When mice were treated with $\operatorname{drug}(\mathrm{s})$ after SNL (twice a day from day 1 to day 13) and the Von Frey tests were done every other day, we found that oxycodone by itself at a lower dose, i.e., $1 \mathrm{mg} / \mathrm{kg}$, improved the allodynia partially, as shown in the 

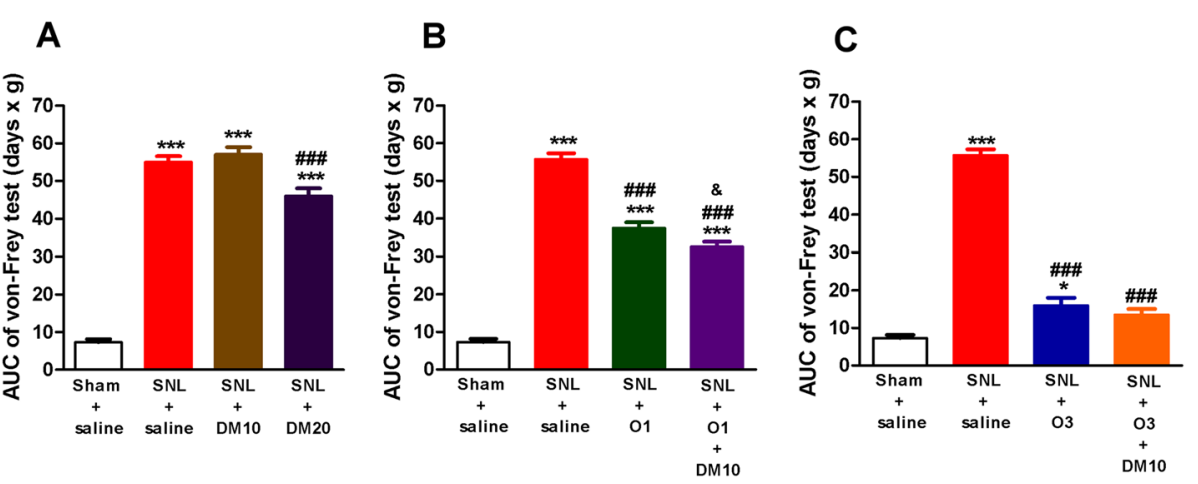

Fig. $3 \mathrm{DM}(10 \mathrm{mg} / \mathrm{kg}$, i.p.) enhanced the acute effect of oxycodone (1 mg/kg, s.c.) on SNL-induced allodynia. The ipsilateral paw withdrawal pressure was determined $30 \mathrm{~min}$ after saline or drug administration every other day after SNL. (a) effects of DM10 (DM, 10 mg/kg, i.p.) or DM20 (DM, 20 mg/kg, i.p.); (b) effects of $\mathrm{O} 1$ (oxycodone, $1 \mathrm{mg} / \mathrm{kg}$, s.c.) or O1 + DM10; (c) effects of O3 (oxycodone, 3 mg/kg, s.c.) or O3 + DM10. Data are presented as means \pm S.E.M. $(n=5-9)$. One-way ANOVA and Newman-Keuls test were used to analyze the data. ${ }^{*} P<0.05,{ }^{* * *} p<0.001$ vs. Sham + saline group; ${ }^{\# \# \#} p<0.001$ vs. SNL + saline group; ${ }^{\&} p<0.05$ vs. SNL +01 group

Fig. 3b. Co-administration of DM (10 mg/kg, i.p.) enhanced the acute effect of oxycodone $(1 \mathrm{mg} / \mathrm{kg}$, s.c.) minimally but significantly (Fig. $3 \mathrm{~b}, p<0.05$ ). However, this combined treatment did not improve the chronic effect of oxycodone $(1 \mathrm{mg} / \mathrm{kg}$, s.c.) if tested $1 \mathrm{~h}$ before oxycodone administration every other day, as shown in Fig. 4b.

The acute anti-allodynic effects of oxycodone at a higher dose of $3 \mathrm{mg} / \mathrm{kg}$ were shown in Fig. 3c. It could be seen that the AUC value of oxycodone $(3 \mathrm{mg} / \mathrm{kg})$ was much less than that in the SNL + saline group $(p<0.001)$ but still larger than that in the sham + saline group (Fig. 3c, $p<0.05$ ). There is an apparent enhancement of anti-allodynic effects of $3 \mathrm{mg} / \mathrm{kg}$ oxycodone with the co-administration of DM $(10 \mathrm{mg} / \mathrm{kg})$ as demonstrated by no significant difference in the AUC value between this group and that of the sham + saline group (Fig. 3c). More importantly, when the Von Frey tests were done $1 \mathrm{~h}$ before drug treatment every other day, co-administration of DM $(10 \mathrm{mg} / \mathrm{kg})$ with
$3 \mathrm{mg} / \mathrm{kg}$ of oxycodone significantly enhanced the chronic anti-allodynic effects of oxycodone, as shown in Fig. 4c, suggesting that this combined use of DM $(10 \mathrm{mg} / \mathrm{kg})$ with oxycodone ( $3 \mathrm{mg} / \mathrm{kg}$, s.c.) could further alleviate the development of chronic allodynia.

\section{Oxycodone suppressed the SNL-induced activation of astrocytes and microglia}

Morphological changes of astrocytes and microglia during allodynia under SNL-induced neuropathic pain were examined by carrying out immunohistofluoresence studies. In the sham-operated group (sham + saline), GFAPimmunopositive astrocytes had a less ramified morphology. In contrast, SNL induced significant activation of astrocytes manifested by a strong GFAP immunoreactivity and hypertrophic morphology in the dorsal spinal cord (L5) of ipsilateral side, which could be seen on day 14 after SNL surgery (Fig. 5a). Quantification of immunoreactivity
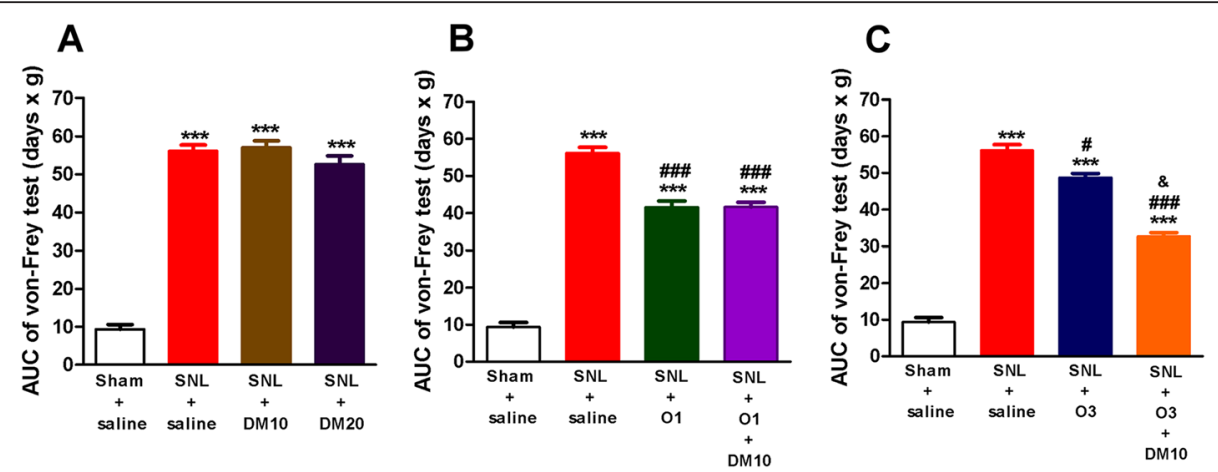

Fig. 4 DM (10 mg/kg, i.p.) enhanced the chronic effects of oxycodone (3 mg/kg, s.c.) on SNL-induced allodynia. The ipsilateral paw withdrawal pressure was determined every other day after SNL at about $1 \mathrm{~h}$ before daily saline or drug administration. (a) effects of DM10 (DM, $10 \mathrm{mg} / \mathrm{kg}$, i.p.) or DM20 (DM, 20 mg/kg, i.p.); (b) effects of O1 (oxycodone, 1 mg/kg, s.c.) or O1 + DM10; (c) effects of O3 (oxycodone, 3 mg/kg, s.c.) or O3 + DM10. Data are presented as means \pm S.E.M. $(n=5-9)$. One-way ANOVA and Newman-Keuls test were used to analyze the data. ${ }^{* * *} P<0.001 \mathrm{vs}$. Sham + saline group; ${ }^{\#} p<0.05,{ }^{\# \# \#} p<0.001$ vs. SNL + saline group; ${ }^{\circledR} p<0.05$ vs. SNL +03 group 
A

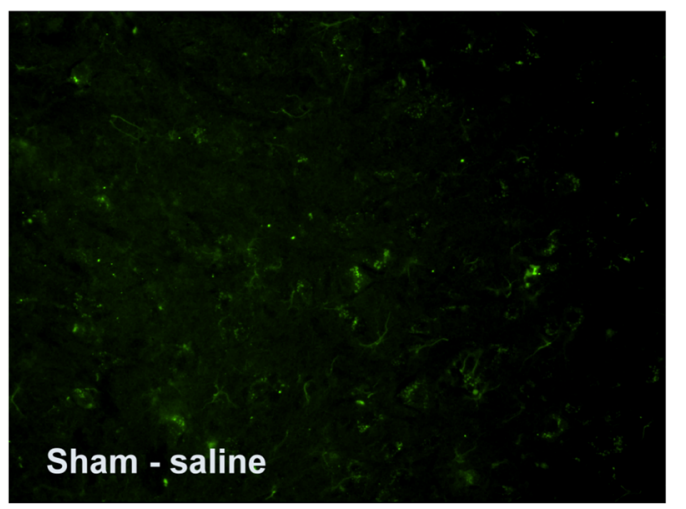

contralateral

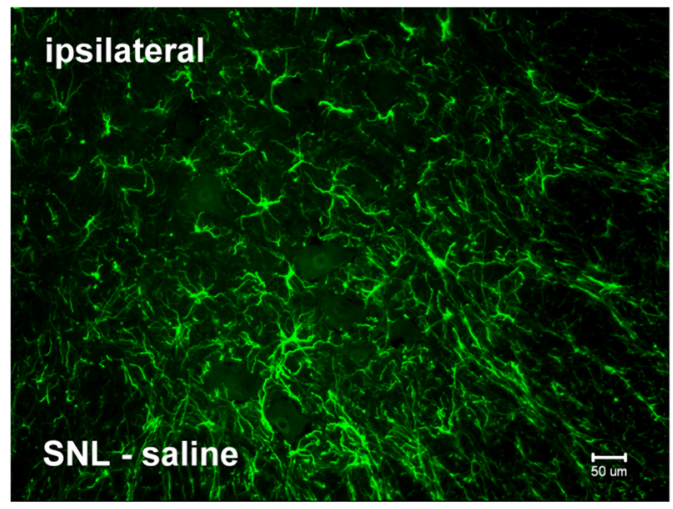

SNL - saline
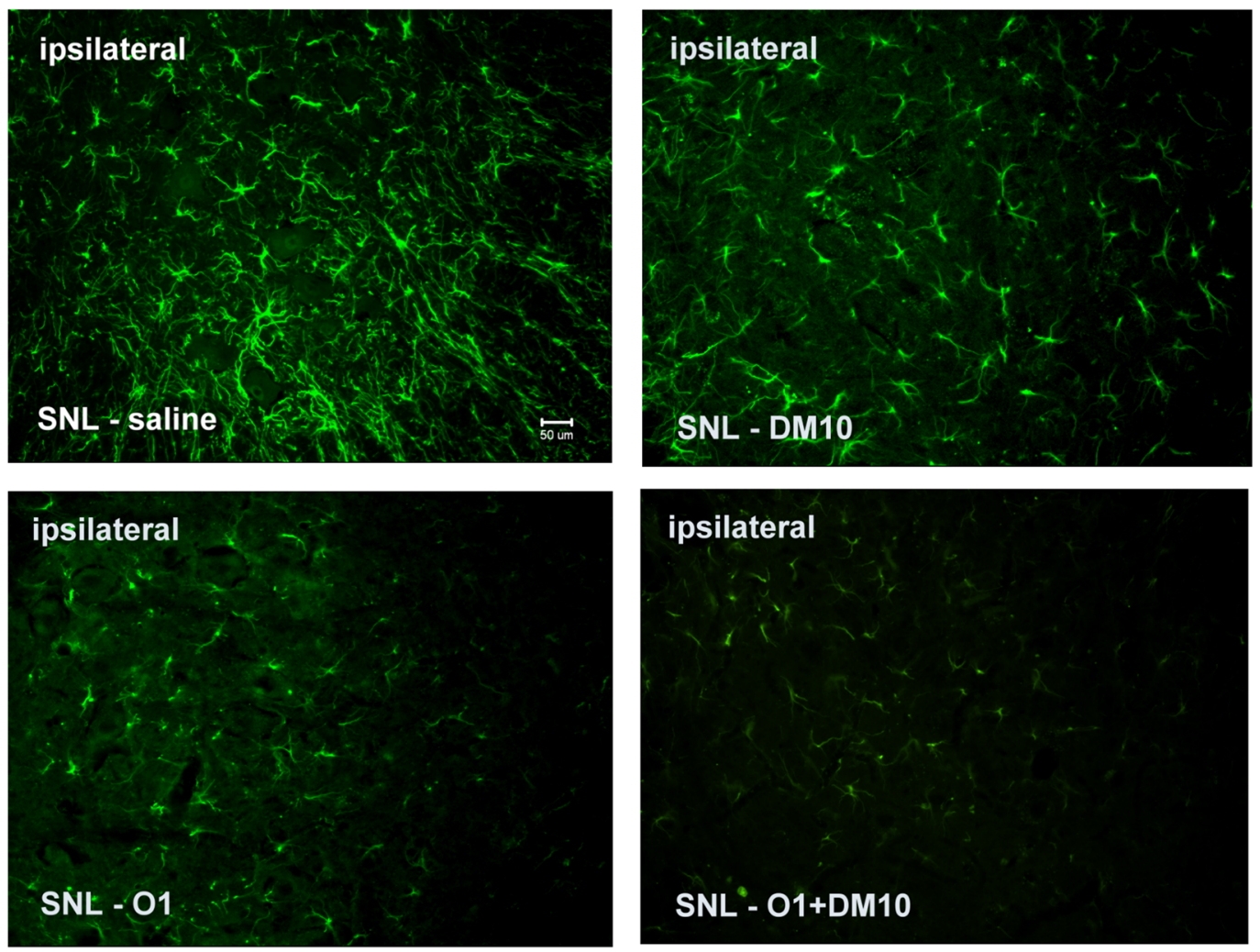

B

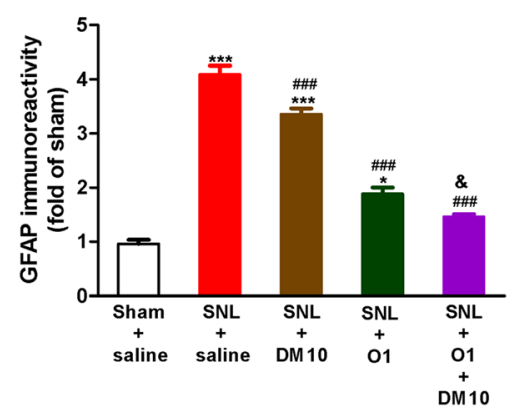

Fig. 5 (See legend on next page.) 
(See figure on previous page.)

Fig. 5 Co-administration of DM (10 mg/kg, i.p.) and oxycodone (1 mg/kg, s.c.) enhanced the effect of oxycodone to suppress SNL-induced activation of astrocytes in the L5 spinal cord dorsal horn. (a) Representative immunofluorescent images of astrocytes stained with GFAP (green; marker for activated astrocyte) on day 14 is shown for the following groups: Sham (ipsilateral), SNL (contralateral), SNL (ipsilateral), SNL-DM10 (DM 10 mg/kg, i.p.; ipsilateral), SNL-O1 (oxycodone $1 \mathrm{mg} / \mathrm{kg}$, s.C.; ipsilateral), and SNL-O1 + DM10 (co-administration of oxycodone and DM; ipsilateral) (magnification: 20X). Scale bar, $50 \mu \mathrm{m}$. (b) Quantification of GFAP-immunoreactivity after normalization for each group compared with control group (Sham + saline) on day 14. Data are presented as means \pm S.E.M. ( $n \geq 5$ ). One-way ANOVA and Newman-Keuls test were used to analyze the data. ${ }^{*} p<0.05,{ }^{* *} p<0.01,{ }^{* * *} p<0.001$ vs. Sham + saline group; ${ }^{\#} p<0.05,{ }^{\# \# \#} p<0.001$ vs. SNL + saline group; ${ }^{\&} p<0.05$ vs. SNL +01 group

by measuring the intensity of the staining indicated significant increase of GFAP immunoreactivity by SNL (4.1-fold on day 14), as compared with the sham control group (sham + saline) (Fig. 5b). Daily treatment with oxycodone $(1 \mathrm{mg} / \mathrm{kg})$ significantly suppressed SNL-induced activation of astrocytes (Fig. 5a, b).

The microglia with a resting ramified morphology by staining with a marker (iba1) were observed at the ipsilateral side of the dorsal spinal cord of sham-operated mice on day 14 (Fig. 6a). On the other hand, hypertrophic and amoeboid morphology of microglia in SNL mice were seen on day 14 , indicating that microglia were more activated in SNL mice than those in sham-operated mice (Fig. 6a). The immunoreactivity of iba1 was also markedly increased in the ipsilateral L5 spinal cord dorsal horn (4.6-fold increase) after spinal nerve ligation for 14 days ( $\mathrm{SNL}+$ saline group), as compared with the sham control group (sham + saline) (Fig. 6b). Oxycodone (1 mg/ $\mathrm{kg}$ ) significantly suppressed SNL-induced microglia activation, as shown in Fig. 6b.

\section{DM potentiated the effect of oxycodone in suppressing the SNL-induced activation of astrocytes and microglia} Daily treatment with DM $(10 \mathrm{mg} / \mathrm{kg})$ by itself slightly but significantly suppressed SNL-induced activation of astrocytes (Fig. 5a). After daily co-administration of oxycodone $(1 \mathrm{mg} / \mathrm{kg})$ with DM $(10 \mathrm{mg} / \mathrm{kg})$, some activated astrocytes were reversed to the resting state, as indicated by a further decrease in GFAP-positive cells (Fig. 5a, b).

DM (10 mg/kg) alone did not suppress the SNL-induced microglia activation, as shown in Fig. 6b. However, coadministration of DM with oxycodone potentiated the effect of oxycodone and further inhibited the SNL-induced microglia activation to the control (sham + saline) level (Fig. 6b). These results suggest that DM can enhance the effects of oxycodone $(1 \mathrm{mg} / \mathrm{kg})$ in suppressing the SNLinduced activation of both microglia and astrocytes. Since this effect of $\mathrm{DM}+\mathrm{O} 1$ has reached the maximal effect, we did not further do the immunostaining for $\mathrm{DM}+\mathrm{O} 3$ group.

\section{The plasma level of SNL-induced pro-inflammatory cytokines was reduced by oxycodone or co-administration of DM with oxycodone}

Spinal-nerve injury induces rapid production and release of proinflammatory mediators [28, 29]. Therefore, whether co-administration of DM with oxycodone would enhance the effect of oxycodone on pro-inflammatory cytokines in plasma for each group on day 2 and day 6 after SNL surgery were determined. As shown in Fig. 7, SNL induced a significantly higher plasma level in all three proinflammatory cytokines we measured - i.e., interleukin-6 (IL-6, Fig. 7a), interleukin-1 $\beta$ (IL-1 $\beta$, Fig. 7b), and tumor necrosis factor alpha (TNF- $\alpha$, Fig. 7c) - on day 2 and day 6 after spinal nerve ligation. These increases were suppressed by either the treatment of oxycodone alone $(1 \mathrm{mg} / \mathrm{kg})$ or co-administration of DM $(10 \mathrm{mg} / \mathrm{kg})$ with oxycodone (1 mg/kg) (Fig. 7a, b, c). DM (10 mg/kg) by itself reduced the plasma concentration of IL-1 $\beta$ (Fig. 7b) and TNF- $\alpha$ (Fig. 7c) on day 2 and/or day 6 after surgery, but did not affect the plasma level of IL-6. When DM $(10 \mathrm{mg} / \mathrm{kg})$ was co-administered with oxycodone, it seemed to further decrease the plasma levels of IL- $1 \beta$ and TNF- $\alpha$, which were already suppressed by oxycodone $(1 \mathrm{mg} / \mathrm{mg})$, although this did not achieve statistical significance.

\section{Discussion}

The present study demonstrates that acute administration of oxycodone (1-5 mg/kg, s.c.) suppressed SNL-induced mechanical allodynia in a dose-dependent manner. DM at a low dose $(10 \mathrm{mg} / \mathrm{kg}$, i.p.) potentiated this acute effect of oxycodone. More importantly, it also alleviated the development of chronic allodynia better than use of oxycodone (medium dose, $3 \mathrm{mg} / \mathrm{kg}$, s.c.) alone. We found that chronic oxycodone significantly suppressed the activation of astrocytes and microglia in the spinal cord and also the plasma level of proinflammatory cytokines (IL-6, IL-1 $\beta$ and TNF$\alpha)$. Furthermore, co-administration of DM with oxycodone showed better effects than oxycodone alone in suppressing the SNL-induced activation of astrocytes and microglia in the dorsal horn of spinal cord and also showed a trend to enhance the effect of oxycodone on decreasing the plasma level of proinflammatory cytokines.

Oxycodone is an agonist acting on opioid receptors which are all coupled to the $G$ proteins and distributed in the central and peripheral nervous system [30]. Oxycodone has been used in clinic for the treatment of cancer and neuropathic pain for many years [6]. Similar to other opiate drugs, oxycodone at high doses may have many side effects, including sedation, dizziness, nausea, 

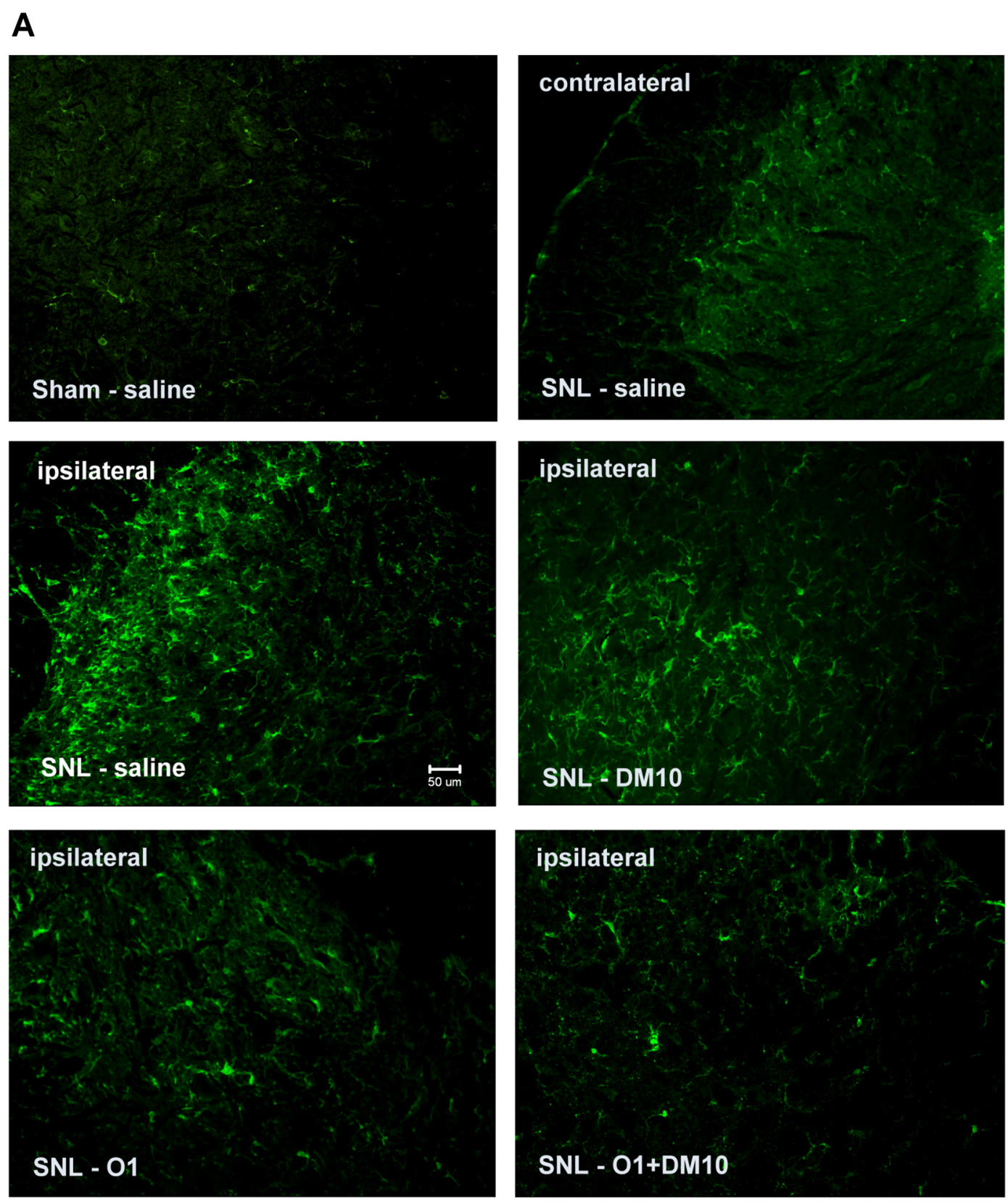

B

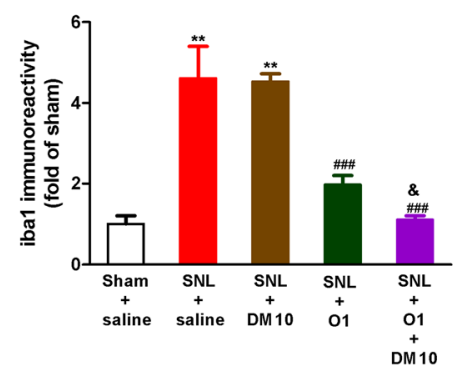

Fig. 6 (See legend on next page.) 
(See figure on previous page.)

Fig. 6 Co-administration of DM (10 mg/kg, i.p.) and oxycodone (1 mg/kg, s.c.) enhanced the effect of oxycodone to suppress SNL-induced activation of microglia in the $\mathrm{L} 5$ spinal cord dorsal horn. (a) Representative immunofluorescent images of microglia stained with iba1 (green; marker for activated microglia) on day 14 is shown for the following groups: Sham (ipsilateral), SNL (contralateral), SNL (ipsilateral), SNL-DM10 (DM 10 mg/kg, i.p.; ipsilateral), SNL-O1 (oxycodone 1 mg/kg, s.c.; ipsilateral), and SNL-O1 + DM10 (co-administration of oxycodone and DM; ipsilateral) (magnification: 20X). Scale bar, $50 \mu \mathrm{m}$. (b) Quantification of iba1-immunoreactivity after normalization for each group compared with control group (Sham + saline) on day 14. Data are presented as means \pm S.E.M. $(n \geq 5)$. One-way ANOVA and Newman-Keuls test were used to analyze the data. ${ }^{*} p<0.05,{ }^{* *} p<0.01,{ }^{* * *} p<0.001$ vs.

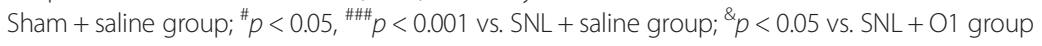

vomiting, constipation, respiratory depression, dependence, and tolerance.

After peripheral nerve injury, spinal sensory neurons (DRG neurons) increased sodium-channel expression on sensitized primary afferents leads to increase of glutamate release from the nerve endings. Glutamate, released from pre-synaptic terminal, binds post-synaptic ionotropic and metabotropic receptors, leading to calcium influx through NMDA and AMPA receptors and activate protein kinase which may contribute to increase gain in the pain transmission system [31]. DM is a commonly used antitussive drug. It acts as a low-affinity non-competitive NMDA receptor antagonist and a high affinity sigma-1 receptor agonist, and it suppresses glutamate-induced excitotoxicity in the CNS and spinal regions [13]. Structurally, it is closely related to levorphanol, codeine, and morphine, but is dextrorotary in form. Therefore, it has low affinity for opioid receptors and is not considered to be addictive.
NMDA receptor antagonists (such as MK-801 and ketamine) and sigma receptor agonists have been reported to have anti-inflammatory effects $[32,33]$. In our results, acute administration of DM alone at a dose of $10 \mathrm{mg} / \mathrm{kg}$ (i.p.) did not show a significant anti-allodynic effect in SNL mice, whereas acute administration of DM at a dose of $20 \mathrm{mg} / \mathrm{kg}$ (i.p.) elicited a slight but significant antiallodynic effect in this model (Fig. 3a). Recently, several clinical studies have shown that high doses of DM (270$400 \mathrm{mg} /$ day) have analgesic effects to neuropathic pain with traumatic origin or diabetic neuropathy, but not with post-herpetic neuralgia [34, 35]. Additionally, low doses of DM (90 mg/day or less) did not relieve chronic neuropathic pain [36] or neuropathic pain resulting from cancer [37]. In rat studies, DM (40 mg/kg, i.p.) and its metabolite dextrophan (20-40 mg/kg, i.p.) induced PCP-like side effects (memory and psychotomimetic disturbances); but 10-30 $\mathrm{mg} / \mathrm{kg}$ (i.p.) of DM did not impair reference

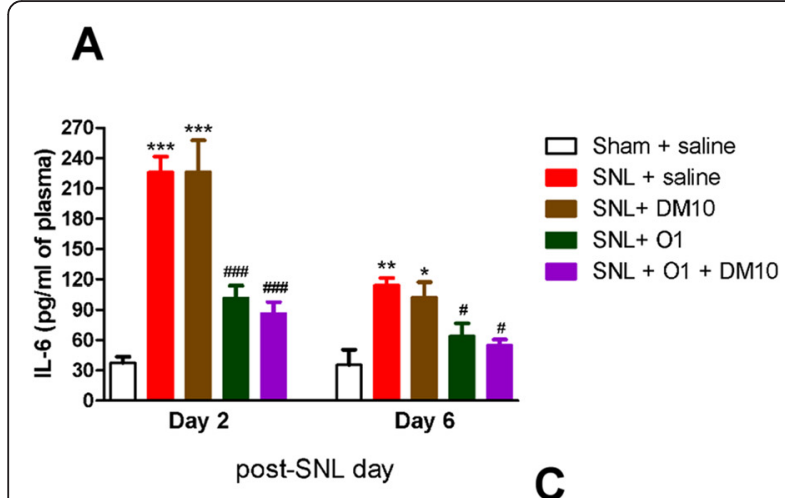

\section{B}
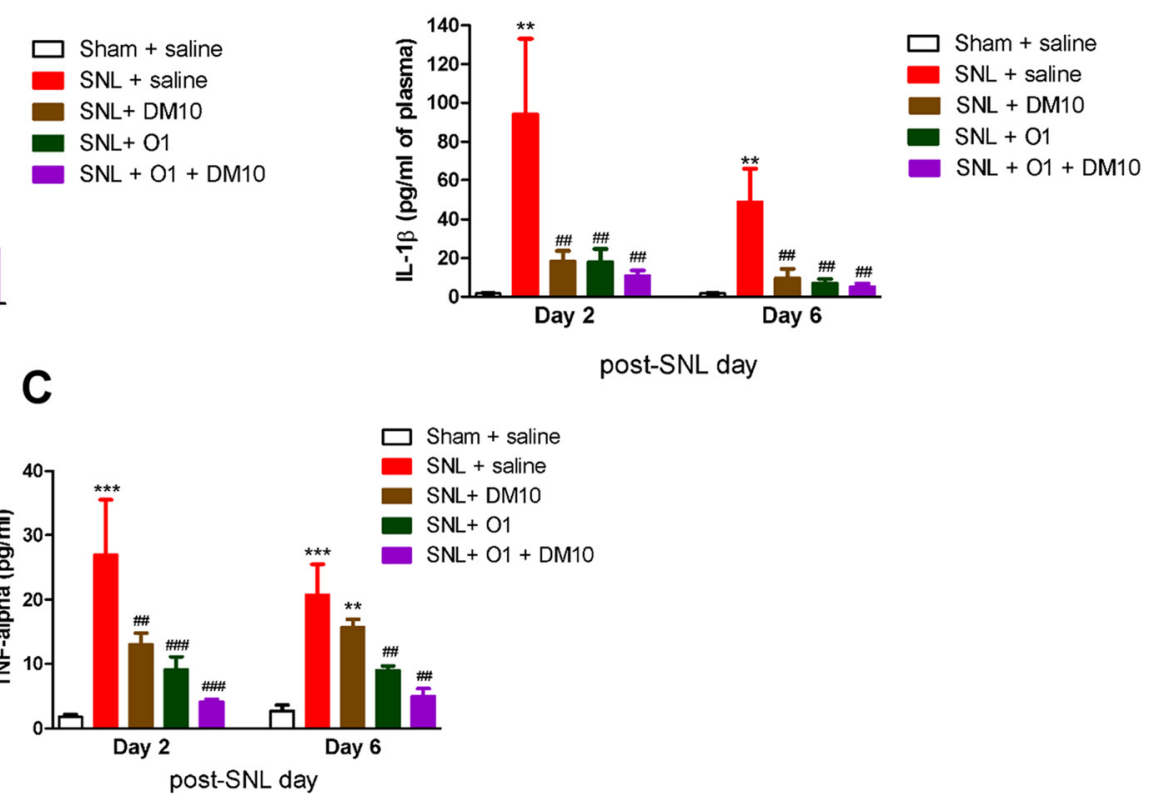

Fig. 7 Effects of DM (10 mg/kg, i.p.) and oxycodone (1 mg/kg, s.c.) on SNL-induced plasma level of pro-inflammatory cytokines: (a) IL-6, (b) IL-1 $\beta$, and (c) TNF-a on day 2 (D2) and day 6 (D6) after SNL surgery. Data are presented as means \pm S.E.M. $(n=7-12)$. One-way ANOVA and Newman-Keuls test were used to analyze the data. ${ }^{*} P<0.05 ;{ }^{* *} p<0.01 ;{ }^{* * * *} p<0.001 \mathrm{vs}$. Sham + saline group; ${ }^{\#} p<0.05 ;{ }^{\# \#} p<0.01 ; \# \# p 0.001 \mathrm{vs}$. SNL + saline group 
memory [38]. Albers et al. (1992) reported that adverse effects of DM seem to be dose related [39]. It is well known that DM is metabolized by O-demethylation through cytochrome P450 2D6 (CYP2D6) to form its active metabolite, dextrophan, and by N-demethylation to form 3-methoxymorphinan, through CYP3A4 [40]. Dextrophan and 3methoxymorphinan is then further $\mathrm{N}$-demethylation and O-demethylation through CYP3A4 and CYP2D6 to form 3-hydroxymorphinan [41]. Therefore, use of high doses of DM may produce phencyclidine (PCP)-like effects from the metabolic conversion of DM to its metabolite, dextrophan. In the current study, we selected a low dose of DM $(10 \mathrm{mg} / \mathrm{kg}$, i.p.; DM10), which did not produce a significant anti-allodynic effect by itself, so that we could investigate whether it would potentiate the acute and/or chronic effects of oxycodone on suppressing neuropathic pain with minimal side effects.

The acute effects of drug(s) in this study were tested 30 min after drug(s) administration every other day. DM10 could potentiate the acute anti-allodynic effects of oxycodone $(1 \mathrm{mg} / \mathrm{kg})$ when tested $30 \mathrm{~min}$ after drug administration as shown in Fig. 3b. Since the acute antiallodynic effects of oxycodone at higher dose $(3 \mathrm{mg} / \mathrm{kg})$ was already very good, we could not see further potentiated effect of DM10 (Fig. 3c) at this dose of oxycodone. Although we did not carry out the pharmacokinetic study in mice, we surmise that the acute effects would not last long because the half-life $\left(t_{1 / 2}\right)$ for the elimination of oxydocone is only $0.52 \pm 0.04 \mathrm{~h}$ in S.D. rats [42] and $3.7 \pm 2.3 \mathrm{~h}$ in humans [43]. Therefore, when we tested for the oxycodone effect about $1 \mathrm{~h}$ before daily drug(s) administration in the morning, this can serve as a measure for the long-term effects of drug(s) on SNLinduced neuropathic pain. In terms of treatment of chronic neuropathic pain, this is a more important measure than the acute effects of drug(s) and we found that combined treatment of DM10 with $3 \mathrm{mg} / \mathrm{kg}$ of oxycodone significantly alleviate chronic allodynia, better than oxycodone alone (3 $\mathrm{mg} / \mathrm{kg}$, s.c.) (Fig. 4c). We did not see the potentiated anti-allodynia effect of DM on $1 \mathrm{mg} / \mathrm{kg}$ of oxycodone (Fig. $4 \mathrm{~b}$ ) when we tested $1 \mathrm{~h}$ before drug administration. It certainly needs further investigation.

It has been reported that spinal damage and peripheral nerve damage both lead to physiological and morphological activation of glial cells, particularly astrocytes and microglia [44]. This activation could be initiated by the release of proinflammatory cytokines (IL-1 $\beta$, IL- 6 and $\mathrm{TNF} \alpha$ ), glutamate and nitric oxide (NO) from glial cells. These mediators can initiate and maintain neuropathic pain, inducing hyperexcitability of nociceptive neurons in the spinal cord dorsal horn. Increased expression of astrocyte markers (i.e., GFAP) and microglia markers (iba1) have been observed in many neuropathic pain models, such as chronic constriction injury (CCI), partial sciatic nerve ligation (PSNL) [45], and spared nerve injury (SNI) [46]. Ma \& Quirion also reported a slight increase in GFAP immunoreactivity of astrocytes on the ipsilateral L4-5 spinal cord dorsal horn one week after PSNL, but a dramatic increase of GFAP immunoreactivity 3 weeks after PSNL [47]. The activation of glial was shown to be directly involved in neuropathic pain, since glial inhibitors exhibited anti-allodynic properties [48]. In our current study, both astrocytes and microglia activation induced by SNL caused changes in morphology, and increased the immunoreactivity of GFAP and iba1 at the ipsilateral spinal cord dorsal horn on day 14 after spinal nerve ligation (Figs. 5 and 6). We did not determine the activation of astrocytes or microglia during the early period after SNL, because the chronic effects of drug(s) could be seen only after 3 days of SNL. Chronic oxycodone treatment (1 mg/ $\mathrm{kg}$, s.c.) significantly decreased the activated astrocytes and microglia as we observed on day 14. A recent study has shown that oxycodone maintained a long-term and strong analgesic effect whereas the analgesic effect of morphine gradually decreased after chronic treatment. This longterm analgesic effect of oxycodone was due to upregulation of $\mathrm{GABA}_{\mathrm{B}}$ receptor expression in DRG neuron under vincristine-induced neuropathic pain in rats [11]. A recent report has shown that spinal nerve ligation induced significant decrease of spinal $\mathrm{GABA}_{\mathrm{B}}$ expression which could be prevented by inhibition of microglia activation [10]. In our current study, we found that chronic oxycodone treatment decreased the activation of glial cells and it was consistent with this report. Co-administration of DM with oxycodone $(1 \mathrm{mg} / \mathrm{kg}$, s.c.) reversed the morphology of activated glial cells in SNL mice and further decreased the activated astrocytes and microglia to almost the same level as in the control group (sham + saline) (Figs. 5 and 6). This effect of DM may account for its effect on enhancing the anti-allodynic effect of oxycodone acutely and chronically. Several studies have reported that nerve injury increases expression and secretion of proinflammatory cytokines, TNF- $\alpha$ [49], IL-1 $\beta$ [50], and IL-6 [51], which are required for the development of pain hypersensitivity. It has been also demonstrated that accumulation of morphologically activated glial cells (microglia and astrocytes) releases proinflammatory cytokines (TNF- $\alpha$ and IL-1 $\beta$ ) in the spinal dorsal horn. TNF- $\alpha$ and IL-1 $\beta$ not only enhance excitatory neurotransmitter (i.e., glutamate) but also suppress inhibitory neurotransmitter release from synaptic terminals and increase the activity of NMDA receptors and its currents in lamina II neurons [52]. It has been reported that DM $(12.5 \mathrm{mg} / \mathrm{kg}$, i.p.) inhibits inflammatory mediators, including cytokines (TNF- $\alpha$, IL- $1 \beta$ and IL-6) and chemokines in sepsis mice model [53]. Furthermore, our recent clinical study showed that DM (60-120 mg/day, oral) attenuated 
plasma cytokine TNF- $\alpha$, which has been increased in methadone-treated heroin addicts [54]. Our present study demonstrates that SNL induced high plasma levels of IL6 , IL- $1 \beta$, and TNF- $\alpha$, and chronic oxycodone $(1 \mathrm{mg} / \mathrm{kg}$, s.c.) suppressed all of them significantly (Fig. 7). DM by itself significantly suppressed the plasma levels of TNF- $\alpha$ and IL-1 $\beta$ but not of IL- 6 . We also found a trend in which DM potentiated the effect of oxycodone $(1 \mathrm{mg} / \mathrm{kg}$, s.c.) on suppressing the plasma levels of IL- 6, IL- $1 \beta$ and TNF- $\alpha$, although this did not achieve statistical significance.

These results suggest that the mechanism of DM for potentiating the chronic effects of oxycodone on suppressing SNL-induced allodynia may be related to its effects on glial and proinflammatory cytokines. On the other hand, we know that the mechanisms for neuropathic pain may involve many factors other than activation of glial cells and inflammatory mediators, such as central sensitization and long-term potentiation (LTP) of nociceptive C-fibers, lamina I neurons and low threshold mechano-sensitive afferents $[55,56]$, etc. Therefore it is reasonable to see a difference between the degree of the reduction in GFAP-ir or pro-inflammatory cytokines and allodynia as shown in our results.

As we mentioned previously, DM binds to NMDA receptors as a low-affinity non-competitive antagonist and binds to sigma-1 receptor as a high-affinity agonist. NMDA receptors are expressed on both microglia and astrocytes [57], whereas sigma receptors are expressed in microglia [58]. It has been reported that the activation of sigma receptors reduced reactive gliosis following stroke injury in rats [59] and that sigma-1 ligands can modulate several neurotransmitter systems through NMDA receptors [60]. Thus the observed DM effects could be due to both its antagonistic activity on NMDA receptors and agonistic activity on the sigma receptors present in the glial cells.

\section{Conclusions}

In conclusion, our study indicates that DM can potentiate the effects of oxycodone in suppressing SNL-induced allodynia acutely or chronically in mice. Suppression of the overactivation of glial cells (astrocytes and microglia) and the following releases of pro-inflammatory cytokines (IL-6, IL-1 $\beta$, and TNF- $\alpha$ ) might play important roles on this effect. The combination of DM with oxycodone may lower the dose of oxycodone and decrease the side effects of oxycodone, therefore providing beneficial effects in early treatment of neuropathic pain.

\footnotetext{
Abbreviations

AAALAC: Association for Assessment and Accreditation of Laboratory Animal Care International; ARRIVE: Animals in Research Reporting In Vivo Experiments; DM: Dextromethorphan; SNL: Spinal nerve ligation; NMDA: N-methyl-D-aspartate; AUC: Area under curve; GFAP: Glial fibrillary acidic protein; TNF-a: Tumor necrosis factor alpha; IL: Interleukin.
}

\section{Competing interests}

The authors declare that they have no competing interests.

\section{Authors' contributions}

P-PY did the experiments, data analysis and manuscript draft writing. G-CY and EY-KH participated on discussion and manuscript revision. P-YL and $\mathrm{HHL}$ participated on project design, discussion and manuscript revision. $\mathrm{P}$ LT designed the experiments, participated on data discussion, manuscript revision and was responsible for paper submission. All authors read and approved the final manuscript.

\section{Acknowledgements}

This work was supported by a grant from the National Science Council (NSC 100-2320-B-400-002-MY3), Taipei, Taiwan, ROC. We are grateful to Mr. M. Swofford for English editing of the paper.

\section{Author details}

${ }^{1}$ Graduate Institute of Medical Sciences, College of Medicine, Taipei Medical University, 250 Wuxing Street, Taipei City 110, Taiwan. 'Department of Pharmacology, National Defense Medical Center, 161, Sec. 6, Minquan E. Rd. Neihu Dist., Taipei City 114, Taiwan. ${ }^{3}$ Department of Pharmacology, University of Minnesota, 6-120 Jackson Hall, 321 Church St. SE, Minneapolis, MN 55455-0217, USA. ${ }^{4}$ Center for Neuropsychiatric Research, National Health Research Institutes, 35 Keyan Road, Zhunan, Miaoli County, 35053 Taiwan, $\mathrm{ROC}$.

Received: 7 April 2015 Accepted: 10 September 2015

Published online: 22 September 2015

\section{References}

1. Ueda H, Rashid MH. Molecular mechanism of neuropathic pain. Drug News Perspect. 2003;16(9):605-13

2. Dworkin $\mathrm{RH}, \mathrm{O}^{\prime}$ Connor AB, Backonja M, Farrar JT, Finnerup NB, Jensen TS, et al. Pharmacologic management of neuropathic pain: evidence-based recommendations. Pain. 2007;132(3):237-51. doi:10.1016/j.pain.2007.08.033.

3. Jin SX, Zhuang ZY, Woolf CJ, Ji RR. p38 mitogen-activated protein kinase is activated after a spinal nerve ligation in spinal cord microglia and dorsal root ganglion neurons and contributes to the generation of neuropathic pain. J Neurosci. 2003;23(10):4017-22.

4. Tsuda M, Mizokoshi A, Shigemoto-Mogami Y, Koizumi S, Inoue K. Activation of p38 mitogen-activated protein kinase in spinal hyperactive microglia contributes to pain hypersensitivity following peripheral nerve injury. Glia. 2004:45(1):89-95. doi:10.1002/glia.10308.

5. Raghavendra $\mathrm{V}$, Rutkowski MD, DeLeo JA. The role of spinal neuroimmune activation in morphine tolerance/hyperalgesia in neuropathic and shamoperated rats. J Neurosci. 2002;22(22):9980-9.

6. Watson CP, Moulin D, Watt-Watson J, Gordon A, Eisenhoffer J. Controlledrelease oxycodone relieves neuropathic pain: a randomized controlled trial in painful diabetic neuropathy. Pain. 2003;105(1-2):71-8.

7. Gimbel JS, Richards P, Portenoy RK. Controlled-release oxycodone for pain in diabetic neuropathy: a randomized controlled trial. Neurology. 2003;60(6):927-34.

8. Nozaki C, Saitoh A, Kamei J. Characterization of the antinociceptive effects of oxycodone in diabetic mice. Eur J Pharmacol. 2006;535(1-3):145-51. doi:10.1016/j.ejphar.2006.02.002

9. Narita M, Nakamura A, Ozaki M, Imai S, Miyoshi K, Suzuki M, et al. Comparative pharmacological profiles of morphine and oxycodone under a neuropathic pain-like state in mice: evidence for less sensitivity to morphine. Neuropsychopharmacology. 2008;33(5):1097-112. doi:10.1038/sj.npp.1301471.

10. Wu J, Xu Y, Pu S, Jiang W, Du D. p38/MAPK inhibitor modulates the expression of dorsal horn GABA(B) receptors in the spinal nerve ligation model of neuropathic pain. Neuroimmunomodulation. 2011;18(3):150-5. doi:10.1159/000323141

11. Thibault K, Calvino B, Rivals I, Marchand F, Dubaca S, McMahon SB, et al. Molecular mechanisms underlying the enhanced analgesic effect of oxycodone compared to morphine in chemotherapy-induced neuropathic pain. PLoS One. 2014;9(3):e91297. doi:10.1371/journal.pone.0091297.

12. Wang SC, Chou DT, Wallenstein MC. Studies on the potency of various antitussive agents. Agents Actions. 1977;7(3):337-40.

13. Parsons CG, Quack G, Bresink I, Baran L, Przegalinski E, Kostowski W, et al. Comparison of the potency, kinetics and voltage-dependency of a series of 
uncompetitive NMDA receptor antagonists in vitro with anticonvulsive and motor impairment activity in vivo. Neuropharmacology. 1995;34(10):1239-58.

14. Hernandez SC, Bertolino M, Xiao Y, Pringle KE, Caruso FS, Kellar KJ. Dextromethorphan and its metabolite dextrorphan block alpha3beta4 neuronal nicotinic receptors. J Pharmacol Exp Ther. 2000;293(3):962-7.

15. Zhou GZ, Musacchio JM. Computer-assisted modeling of multiple dextromethorphan and sigma binding sites in guinea pig brain. Eur J Pharmacol. 1991;206(4):261-9.

16. Huang EY, Liu TC, Tao PL. Co-administration of dextromethorphan with morphine attenuates morphine rewarding effect and related dopamine releases at the nucleus accumbens. Naunyn Schmiedebergs Arch Pharmacol. 2003;368(5):386-92. doi:10.1007/s00210-003-0803-7.

17. Lue WM, Huang EY, Yang SN, Wong CS, Tao PL. Post-treatment of dextromethorphan reverses morphine effect on conditioned place preference in rats. Synapse. 2007;61(6):420-8. doi:10.1002/syn.20391.

18. Yang PP, Huang EY, Yeh GC, Tao PL. Co-administration of dextromethorphan with methamphetamine attenuates methamphetamineinduced rewarding and behavioral sensitization. J Biomed Sci. 2006;13(5):695-702. doi:10.1007/s11373-006-9096-4.

19. Yang PP, Huang EY, Fu YY, Ho TS, Tao PL. Post-treatment of dextromethorphan on methamphetamine-induced drug-seeking and behavioral sensitization in rats. Synapse. 2012;66(10):858-69. doi:10.1002/syn.21576.

20. Prince DA, Feeser HR. Dextromethorphan protects against cerebral infarction in a rat model of hypoxia-ischemia. Neurosci Lett. 1988;85(3):291-6.

21. Karimi G, Tabrizian K, Rezaee R. Evaluation of the analgesic effect of dextromethorphan and its interaction with nitric oxide on sciatic nerve ligated rats. J Acupunct Meridian Stud. 2010;3(1):38-42. doi:10.1016/S20052901(10)60006-4

22. Thomas DM, Kuhn DM. MK-801 and dextromethorphan block microglial activation and protect against methamphetamine-induced neurotoxicity. Brain Res. 2005;1050(1-2):190-8. doi:10.1016/j.brainres.2005.05.049.

23. Liu Y, Qin L, Li G, Zhang W, An L, Liu B, et al. Dextromethorphan protects dopaminergic neurons against inflammation-mediated degeneration through inhibition of microglial activation. J Pharmacol Exp Ther. 2003;305(1):212-8. doi:10.1124/jpet.102.043166.

24. Werling LL, Lauterbach EC, Calef U. Dextromethorphan as a potential neuroprotective agent with unique mechanisms of action. Neurologist. 2007;13(5):272-93. doi:10.1097/NRL.0b013e3180f60bd800127893200709000-00004.

25. McGrath JC, Drummond GB, McLachlan EM, Kilkenny C, Wainwright CL. Guidelines for reporting experiments involving animals: the ARRIVE guidelines. Br J Pharmacol. 2010;160(7):1573-6. doi:10.1111/j.14765381.2010.00873.x.

26. Kim SH, Chung JM. An experimental model for peripheral neuropathy produced by segmental spinal nerve ligation in the rat. Pain. 1992;50(3):355-63.

27. Kao JH, Gao MJ, Yang PP, Law PY, Loh HH, Tao PL. Effect of naltrexone on neuropathic pain in mice locally transfected with the mutant $\mu$-opioid receptor gene in spinal cord. Br J Pharmacol. 2015;172(2):630-41. doi:10.1111/bph.2015.172.issue-2.

28. Thacker MA, Clark AK, Marchand F, McMahon SB. Pathophysiology of peripheral neuropathic pain: immune cells and molecules. Anesth Analg 2007;105(3):838-47. doi:10.1213/01.ane.0000275190.42912.37.

29. Austin PJ, Moalem-Taylor G. The neuro-immune balance in neuropathic pain: involvement of inflammatory immune cells, immune-like glial cells and cytokines. J Neuroimmunol. 2010;229(1-2):26-50. doi:10.1016/ j.jneuroim.2010.08.013.

30. Yoburn BC, Shah S, Chan K, Duttaroy A, Davis T. Supersensitivity to opioid analgesics following chronic opioid antagonist treatment: relationship to receptor selectivity. Pharmacol Biochem Behav. 1995;51(2-3):535-9.

31. Bridges $D$, Thompson SW, Rice AS. Mechanisms of neuropathic pain. $\mathrm{Br}$ J Anaesth. 2001;87(1):12-26.

32. Hall AA, Herrera Y, Ajmo Jr CT, Cuevas J, Pennypacker KR. Sigma receptors suppress multiple aspects of microglial activation. Glia. 2009;57(7):744-54. doi:10.1002/glia.20802.

33. Liu CH, Cherng $\mathrm{CH}$, Lin SL, Yeh CC, Wu CT, Tai YH, et al. N-methyl-Daspartate receptor antagonist MK-801 suppresses glial pro-inflammatory cytokine expression in morphine-tolerant rats. Pharmacol Biochem Behav. 2011;99(3):371-80. doi:10.1016/j.pbb.2011.05.016.
34. Nelson KA, Park KM, Robinovitz E, Tsigos C, Max MB. High-dose oral dextromethorphan versus placebo in painful diabetic neuropathy and postherpetic neuralgia. Neurology. 1997;48(5):1212-8.

35. Carlsson KC, Hoem NO, Moberg ER, Mathisen LC. Analgesic effect of dextromethorphan in neuropathic pain. Acta Anaesthesiol Scand. 2004;48(3):328-36. doi:10.1111/j.0001-5172.2004.0325.x.

36. McQuay HJ, Carroll D, Jadad AR, Glynn CJ, Jack T, Moore RA, et al. Dextromethorphan for the treatment of neuropathic pain: a double-blind randomised controlled crossover trial with integral n-of-1 design. Pain. 1994:59(1):127-33.

37. Mercadante S, Casuccio A, Genovese G. Ineffectiveness of dextromethorphan in cancer pain. J Pain Symptom Manage. 1998;16(5):317-22.

38. Dematteis M, Lallement G, Mallaret $M$. Dextromethorphan and dextrorphan in rats: common antitussives-different behavioural profiles. Fundam Clin Pharmacol. 1998;12(5):526-37.

39. Albers GW, Saenz RE, Moses Jr JA. Tolerability of oral dextromethorphan in patients with a history of brain ischemia. Clin Neuropharmacol. 1992;15(6):509-14.

40. Ramachander G, Williams FD, Emele JF. Determination of dextrorphan in plasma and evaluation of bioavailability of dextromethorphan hydrobromide in humans. J Pharm Sci. 1977;66(7):1047-8.

41. Jones DR, Gorski JC, Hamman MA, Hall SD. Quantification of dextromethorphan and metabolites: a dual phenotypic marker for cytochrome P450 3A4/5 and 2D6 activity. J Chromatogr B Biomed Appl. 1996;678(1):105-11.

42. Huang L, Edwards SR, Smith MT. Comparison of the pharmacokinetics of oxycodone and noroxycodone in male dark agouti and Sprague-Dawley rats: influence of streptozotocin-induced diabetes. Pharm Res. 2005;22(9):1489-98. doi:10.1007/s11095-005-6154-y.

43. Poyhia R, Olkkola KT, Seppala T, Kalso E. The pharmacokinetics of oxycodone after intravenous injection in adults. Br J Clin Pharmacol. 1991;32(4):516-8.

44. Woolf CJ, Mannion RJ. Neuropathic pain: aetiology, symptoms, mechanisms, and management. Lancet. 1999;353(9168):1959-64. doi:10.1016/S01406736(99)01307-0.

45. Coyle DE. Partial peripheral nerve injury leads to activation of astroglia and microglia which parallels the development of allodynic behavior. Glia. 1998;23(1):75-83.

46. Vega-Avelaira D, Moss A, Fitzgerald M. Age-related changes in the spinal cord microglial and astrocytic response profile to nerve injury. Brain Behav Immun. 2007;21(5):617-23. doi:10.1016/j.bbi.2006.10.007.

47. Ma W, Quirion R. Partial sciatic nerve ligation induces increase in the phosphorylation of extracellular signal-regulated kinase (ERK) and c-Jun Nterminal kinase (JNK) in astrocytes in the lumbar spinal dorsal horn and the gracile nucleus. Pain. 2002;99(1-2):175-84.

48. Sweitzer SM, Schubert P, DeLeo JA. Propentofylline, a glial modulating agent, exhibits antiallodynic properties in a rat model of neuropathic pain. J Pharmacol Exp Ther. 2001;297(3):1210-7.

49. Wagner R, Myers RR. Endoneurial injection of TNF-alpha produces neuropathic pain behaviors. Neuroreport. 1996;7(18):2897-901.

50. Zelenka M, Schafers $M$, Sommer C. Intraneural injection of interleukin-1 beta and tumor necrosis factor-alpha into rat sciatic nerve at physiological doses induces signs of neuropathic pain. Pain. 2005;116(3):257-63. doi:10.1016/ j.pain.2005.04.018.

51. Arruda JL, Colburn RW, Rickman AJ, Rutkowski MD, DeLeo JA. Increase of interleukin-6 mRNA in the spinal cord following peripheral nerve injury in the rat: potential role of $\mathrm{IL}-6$ in neuropathic pain. Brain Res Mol Brain Res. 1998;62(2):228-35.

52. Kawasaki Y, Zhang L, Cheng JK, Ji RR. Cytokine mechanisms of central sensitization: distinct and overlapping role of interleukin-1beta, interleukin-6, and tumor necrosis factor-alpha in regulating synaptic and neuronal activity in the superficial spinal cord. J Neurosci. 2008;28(20):5189-94. doi:10.1523/ JNEUROSCI.3338-07.2008.

53. Li MH, Luo YH, Lin CF, Chang YT, Lu SL, Kuo CF, et al. Dextromethorphan efficiently increases bactericidal activity, attenuates inflammatory responses, and prevents group a streptococcal sepsis. Antimicrob Agents Chemother. 2011;55(3):967-73. doi:10.1128/AAC.00950-10.

54. Chen SL, Lee SY, Tao PL, Chang YH, Chen SH, Chu CH, et al. Dextromethorphan attenuated inflammation and combined opioid use in humans undergoing methadone maintenance treatment. J Neuroimmune Pharmacol. 2012;7(4):1025-33. doi:10.1007/s11481-012-9400-1. 
55. Li L, Rutlin M, Abraira VE, Cassidy C, Kus L, Gong S, et al. The functional organization of cutaneous low-threshold mechanosensory neurons. Cell. 2011;147(7):1615-27. doi:10.1016/j.cell.2011.11.027.

56. Dubin AE, Patapoutian A. Nociceptors: the sensors of the pain pathway. J Clin Invest. 2010;120(11):3760-72. doi:10.1172/jci42843.

57. Pocock JM, Kettenmann H. Neurotransmitter receptors on microglia. Trends Neurosci. 2007;30(10):527-35. doi:10.1016/j.tins.2007.07.007.

58. Nademanee K. Is pulmonary vein isolation by segmental ostial ablation a correct approach for treatment of atrial fibrillation? Heart Rhythm. 2006;3(9):1029-30. doi:10.1016/j.hrthm.2006.06.001.

59. Ajmo Jr CT, Vernon DO, Collier L, Pennypacker KR, Cuevas J. Sigma receptor activation reduces infarct size at $24 \mathrm{~h}$ after permanent middle cerebral artery occlusion in rats. Curr Neurovasc Res. 2006;3(2):89-98.

60. Cobos EJ, Entrena JM, Nieto FR, Cendan CM, Del Pozo E. Pharmacology and therapeutic potential of sigma(1) receptor ligands. Curr Neuropharmacol. 2008;6(4):344-66. doi:10.2174/157015908787386113.

\section{Submit your next manuscript to BioMed Central and take full advantage of:}

- Convenient online submission

- Thorough peer review

- No space constraints or color figure charges

- Immediate publication on acceptance

- Inclusion in PubMed, CAS, Scopus and Google Scholar

- Research which is freely available for redistribution 